\title{
- Exame neurológico em grandes animais. Parte I: Encéfalo
}

\section{- Large animal neurologic examination. Part I: Brain}

\author{
* Alexandre Secorun Borges ${ }^{1}$-CRMV-SP n 0564 \\ Luiz Cláudio NogueiraMendes ${ }^{1}$-CRMV-SP n ${ }^{0} 6112$ \\ Márcio Rubens Graf Kuchembuck ${ }^{2}$-CRMV-SPn 0033 \\ 1 Professor Assistente de Clínica Veterinária \\ Curso de Medicina Veterinária - UNESP - Araçatuba \\ 2 Professor Titular de Clínica Veterinária \\ Faculdade de Medicina Veterinária e Zootecnia - UNESP - Botucatu
}

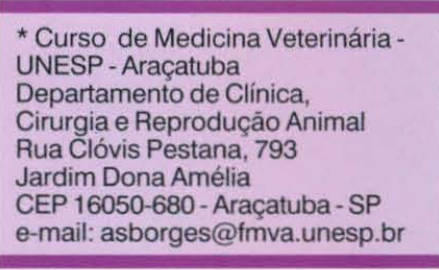

* Curso de Medicina Veterinária UNESP - Araçatuba

Cirurgia e Reproduçāo Anima

Rua Clóvis Pestana, 793

CEP 16050-680 - Araçatuba - SP

e-mail: asborges@fmva.unesp.br

\section{RESUMO}

Neste primeiro artigo abordando o exame neurológico em grandes animais são apresentados dados referentes à neuroanatomia e à neurofisiologia, e o exame das funções encefálicas. No próximo artigo será abordado o exame da medula espinhal desses animais.

Unitermos: neurologia, encéfalo, medula espinhal, arco reflexo, nervos cranianos e sistema nervoso.

\section{Introdução}

$\mathrm{P}$ roblemas neurológicos são freqüentes em bovinos, eqüinos, caprinos e ovinos, sendo o exame neurológico um passo de fundamental importância para localização e diagnóstico de inúmeras enfermidades do sistema nervoso.

O exame é dificultado pelo escasso acesso para avaliação direta, quando comparado a outros sistemas. Isso pode ser percebido já que nenhuma estrutura nervosa pode ser palpada diretamente e, com exceção da papila óptica, também não pode ser visualizada. Outro fator que deve ser levado em consideração é o tamanho dos animais que dificulta a realização de vários tipos de teste, comumente utilizados na avaliação de cães e gatos. Como grande parte dos processos neurológicos em grandes animais não possui um bom prognóstico, uma avaliação mais criteriosa é desestimulada; entretanto, deve-se lembrar que algumas enfermidades apresentam bons resultados quando diagnosticadas e tratadas precocemente (polioencefalomalácia dos bovinos, mieloencefalopatia por protozoários em eqüinos, etc.), além do que um diagnós- tico correto permitirá a adoção de medidas que evitem que outros animais adoeçam.

O objetivo deste artigo é apresentar uma metodologia para realização do exame neurológico e a interpretação dos resultados obtidos, contribuindo para que este exame seja eficiente, produzindo conclusões úteis e confiáveis.

O exame neurológico baseia-se na avaliação do comportamento (estado mental), postura e movimentos (andar, trotar e galopar), pares de nervos cranianos, reações posturais e, quando possível, na realização de reflexos espinhais. Pode-se incluir exames complementares como análise do líquido cefalorraquidiano, radiografias simples ou contrastadas (mielografia), eletroencefalografias, tomografia computadorizada e ressonância magnética (Quadro 1).

\section{Quadro 1}

Ocorrendo a suspeita de uma disfunção neurológica, durante a realização do exame físico, uma avaliação meticulosa do sistema nervoso deve ser realizada. 


\section{Quadro2}

Como as estruturas do sistema nervoso não são diretamente palpadas e com exceção do nervo óptico não são visualizadas, o exame neurológico deve ser realizado tendo como base a resposta obtida em provas específicas da avaliação funcional (isto é, estimula-se as estruturas do sistema nervoso e observa-se a resposta que deve ser classificada como normal ou anormal).

Quando se percebe que o exame neurológico deve ser realizado e interpretado a partir das respostas obtidas em provas específicas da avaliação funcional, e com a familiarização dos procedimentos e testes utilizados, este passa a ser executado rotineiramente e com a mesma

\section{Quadro3}

O sistema nervoso funcionalmente é um sistema de interrelação do animal com o meio ambiente, funciona basicamente como receptor, condutor e processador dos estímulos gerando no final uma determinada resposta.

facilidade do exame dos outros sistemas (respiratório, digestivo, locomotor, etc.). Sempre que soubermos realizar corretamente um teste e conhecermos qual a resposta normal do organismo, saberemos identificar respostas anormais, passo fundamental para um exame bem sucedido (Quadro 2).

Durante o exame neurológico de grandes animais a maior quantidade de informações deve ser obtida da

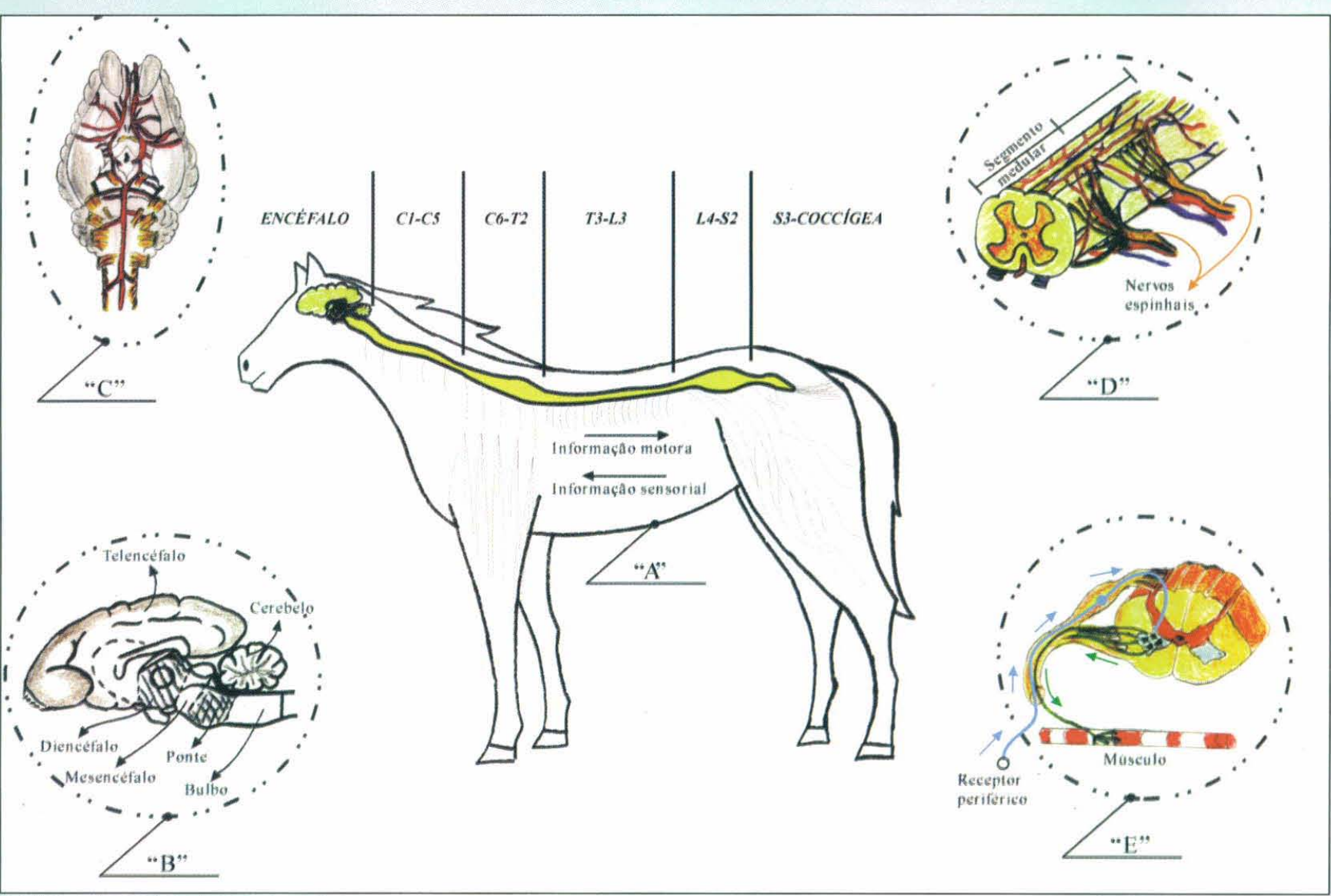

Figura 1A: Eqüino com a representação esquemática em amarelo do sistema nervoso central (encéfalo e medula espinhal) e parte do sistema nervoso periférico (nervos espinhais - cinza). Observa-se a divisão funcional da medula espinhal e o sentido da informação sensorial e motora. Figura 1B: Encéfalo em corte sagital mostrando sua divisão anatomo funcional. Cérebro (telencéfalo + diencéfalo), tronco encefálico (mesencéfalo + ponte + bulbo) e cerebelo.

Figura 1C: Vista ventral do encéfalo com destaque para a emergência dos nervos cranianos (laranja).

Figura 1D: Medula espinhal representada por 2 de seus segmentos, observa-se o $\mathrm{H}$ medular e a presença de artérias, veias e dos nervos espinhais de um dos lados.

Figura 1E: Componentes do arco reflexo espinhal. O esquema mostra a captação de um estímulo em receptor periférico (setas azuis) e sua condução em neurônios sensitivos (no interior de um nervo espinhal), passando pela raiz dorsal. Após entrar na medula espinhal ocorre conexão com o corpo celular do neurônio motor inferior na substância cinzenta da medula espinhal. Esta informação motora é transmitida até o feixe muscular pelo axônio deste NMI (setas verdes) no interior do nervo espinhal. 
BORGES, A.S.; MENDES, L. C. N.; KUCHEMBUCK, M. R. G. Exame neurológico em grandes animais. Part. I: Encéfalo, / Large animal neurologic examination. Part I: Brain. Rev. educ. contin. CRMV-SP / Continuous Education Journal CRMV-SP, São Paulo, volume 2, fascículo 3, p. 004 - 016 , 1999

\begin{tabular}{|l|}
\hline $\begin{array}{l}\text { Quadro 4 - DIFICULDADES DO EXAME } \\
\text { NEUROLÓGICO EM GRANDES ANIMAIS }\end{array}$ \\
\hline Tamanho e temperamento do paciente. \\
Limitada experiência do examinador. \\
No sistema nervoso as respostas apresentam maior \\
correlação com o local da lesão do que com sua causa. \\
Limitadas opções terapêuticas. \\
Seqüelas residuais são menos toleráveis em grandes \\
do que em pequenos animais.
\end{tabular}

anamnese e do exame físico, já que são poucas as vezes que os exames complementares acima citados podem ser utilizados, principalmente quando os animais são avaliados no campo.

\section{Neuroanatomia e Neurofisiologia}

Devemos inicialmente considerar a divisão do sistema nervoso (SN) em sistema nervoso central (SNC) e sistema nervoso periférico (SNP). Como SNC devemos entender o encéfalo e a medula espinhal, sendo o encéfalo o conjunto de estruturas contidas dentro da calota craniana acima do forame magno. $\mathrm{O}$ encéfalo possui a seguinte subdivisão: telencéfalo, diencéfalo, mesencéfalo, ponte, bulbo e cerebelo. O que chamamos geralmente de cérebro é a associação de telencéfalo e diencéfalo (Quadro 3 e Figura 1).

A calota craniana oferece proteção contra traumatismos. Entre o encéfalo e a calota craniana estão justapostas as meninges, sendo a mais externa e espessa denominada dura-mater, a intermediária aracnóide, sob a qual circula o líquido cefalorraquidiano; abaixo desta, e justaposta ao encéfalo, encontra-se a pia-mater. O fluido cefalorraquidiano possui importantes funções fisiológicas, além disso pode espelhar muitas alterações do tecido nervoso, servindo como importante método auxiliar diagnóstico (Quadro 4).

O tronco encefálico é uma área de grande importância para o exame neurológico já que envolve as regiões de mesencéfalo, ponte e bulbo onde se encontra a maior parte dos núcleos dos nervos cranianos (como núcleo entende-se o conjunto de corpos celulares de neurônios dentro do SNC, sendo o seu correspondente no SNP denominado gânglio). Sendo assim, uma lesão neste local, mesmo que pequena, acarretará dano ou alteração na função de mais de um par de nervos cranianos, já que é grande a proximidade entre eles (Quadro 5).

A medula espinhal inicia-se a partir do final do bulbo e possui o mesmo número de segmentos que o número de vértebras (com exceção da medula cervical que é composta por 8 segmentos medulares). Cada segmento pode

\section{Quadro 5 - ENCÉFALO: SUAS PRINCIPAIS DIVISÕES} ANATÔMICAS E RESPECTIVAS FUNÇÕES

TELENCÉFALO: córtex cerebral (frontal: intelecto, comportamento e atividade motora refinada; parietal: nocicepção e propriocepção; occipital: visão; temporal: comportamento e audição) e núcleos basais (conjunto de corpos celulares localizados abaixo do encéfalo, ex: caudado, putamen, etc; com funções relacionadas ao tônus muscular e iniciação e controle da atividade motora).

DIENCÉFALO: hipotálamo (modula o sistema nervoso autônomo, apetite, sede, regulação de temperatura e balanço de eletrólitos), tálamo (é um complexo de vários núcleos que entre outras funções estão relacionados com nocicepção, propriocepção e consciência), subtálamo (sistema reticular ativador relacionado a consciência). O diencéfalo também é - local que abriga o núcleo do nervo olfatório e do nervo óptico.

MESENCÉFALO: relacionado a consciência (sistema reticular ascendente ativador), núcleos de nervos cranianos (III, IV), apresenta também tratos ascendentes e descendentes com presença de atividade motora e sensorial.

PONTE: local onde está localizado o núcleo do nervo trigêmio $(V)$, formação reticular (centros vitais de respiração e sono), tratos ascendentes e descendentes possuindo atividade sensorial e motora.

BULBO: local com maior acúmulo de núcleos de nervos cranianos (VI, VII, VIII, IX, X, XI, XII), tratos ascendentes e descendentes possuindo atividade sensorial e motora.

CEREBELO: coordenação de movimentos, tônus muscular, propriocepção inconsciente e equilíbrio.

ser identificado morfologicamente pois possui um par de nervos espinhais, cada um com uma raiz dorsal (sensitiva) e uma raiz ventral (motora). Esses nervos espinhais são constituídos por neurônios sensitivos e motores.

A medula espinhal pode ser morfológica e funcionalmente dividida em 5 regiões: região cervical (compreendendo os segmentos medulares de $\mathrm{C} 1$ a C5); região cérvico-torácica (também denominada de plexo ou intumescência braquial, segmentos de C6 a T2); região tóraco-lombar (correspondendo aos segmentos medulares de T3 a L3); região lombo-sacra (plexo ou intumescência lombo-sacra, segmentos de L4 a S2); região sacro coccígea (segmento S3 ao último segmento medular). Devese ressaltar que essa divisão corresponde a segmentos medulares e não às vértebras propriamente ditas; tal fato seria sem importância se o tamanho do segmento medular e a vértebra correspondente fossem iguais, porém isso não ocorre em toda a medula espinhal.

No início existe grande correspondência entre tamanho medular e vertebral, sendo que a vértebra e o segmento medular correspondente estão justapostos; porém o tamanho medular vai diminuindo em comparação 
ao tamanho vertebral a partir dos últimos segmentos medulares torácicos. Isso acarreta o término da medula espinhal (em grandes animais) aproximadamente na primeira ou segunda vértebras sacrais. Neste ponto inicia-se a estrutura denominada cauda eqüina, que nada mais é do que o conjunto de nervos espinhais localizados dentro do canal vertebral e que irão estender-se caudalmente até a sua saída.

Observando-se a medula espinal dorsalmente iremos notar que as regiões C6 a T2 e L4 a S2 possuem um volume maior em comparação com as regiões anteriores e posteriores (daí o termo intumescência também utilizado para esta região); isso se deve à grande entrada e saída de neurônios nestas duas regiões, responsáveis pela conexão entre SNC e musculatura dos membros anteriores e posteriores, respectivamente.

A medula espinhal, observada em cortes transversais, demonstra duas regiões facilmente diferenciáveis: região cinzenta correspondente ao $\mathrm{H}$ medular é o local onde se encontram os corpos celulares dos neurônios e a substância branca é o local onde se encontram os axônios agrupados em tratos ou fascículos.

O SNP inclui 12 pares de nervos cranianos originando-se no encéfalo e os diversos pares de nervos espinhais originando-se na medula.

Dentre as estruturas celulares encontradas no SN, o neurônio assume importância fundamental por apresentar a característica de excitação (polarização e despolarização), sendo responsável pelo início e manutenção da atividade neurológica. As células da glia e outras estruturas são fundamentais para a estabilidade, suporte, proteção e nutrição do sistema nervoso, porém para o exame clínico, o neurônio assume a maior importância. O exame neurológico será realizado observando-se a resposta aos estímulos realizados.

Os neurônios podem ser funcionalmente divididos em neurônios sensitivos e motores, sendo estes últimos responsáveis pelo início e manutenção da atividade motora, podendo ser divididos em neurônios motores superiores (NMS) e neurônios motores inferiores (NMI).

A associação entre neurônios sensitivos e neurônios motores permite a realização de arcos reflexos. Reflexos são respostas biológicas normais, espontâneas e praticamente invariáveis, sendo úteis ao organismo. $\mathrm{O}$ arco reflexo é uma resposta básica após a realização de um estímulo e é por meio de suas várias modalidades (reflexos espinhais, reflexos dos nervos cranianos) que o exame neurológico será realizado. $\mathrm{O}$ arco reflexo nada mais é do que uma resposta motora involuntária (sem uma supervisão direta de estruturas ligadas à consciência) frente a um estímulo aplicado a uma determinada estrutura. Basicamente 3 neurônios (em alguns arcos reflexos mais estruturas podem estar envolvidas) são responsáveis pela efetuação de um arco reflexo. Em primeiro lugar, um neurônio sensitivo (aferente) irá captar a informação sensorial e conduzi-la até a medula ou tronco encefálico (dependendo se será um arco reflexo mediado por um nervo espinhal ou craniano, respectivamente) e fará a conexão com um interneurônio, o qual será responsável pela transmissão dessa informação para um neurônio motor (eferente) que efetuará a estimulação de um músculo. Vários reflexos podem ser utilizados para avaliação neurológica como por exemplo o reflexo patelar (espinhal), o palpebral, o pupilar, etc.

\section{Exame clínico}

A sua primeira etapa é a identificação do animal (espécie, raça, sexo, idade, utilização, valor, local de origem e utilização do animal). A anamnese deve detalhar informações referentes ao início dos sinais clínicos, evolução, alimentação, vacinação, tratamentos realizados, doenças anteriores, número de animais acometidos, ambiente, manejo dos animais e número de mortes.

Dentre as informações obtidas, deve-se ressaltar o início dos sinais clínicos e a sua evolução (curso da doença). É muito importante sabermos há quanto tempo começaram as alterações e como eram logo no início do processo, pois algumas vezes iremos atender animais com processos neurológicos severos, podendo estar em decúbito, comatosos ou semicomatosos, dificultando a obtenção de algumas informações (Figura 2).

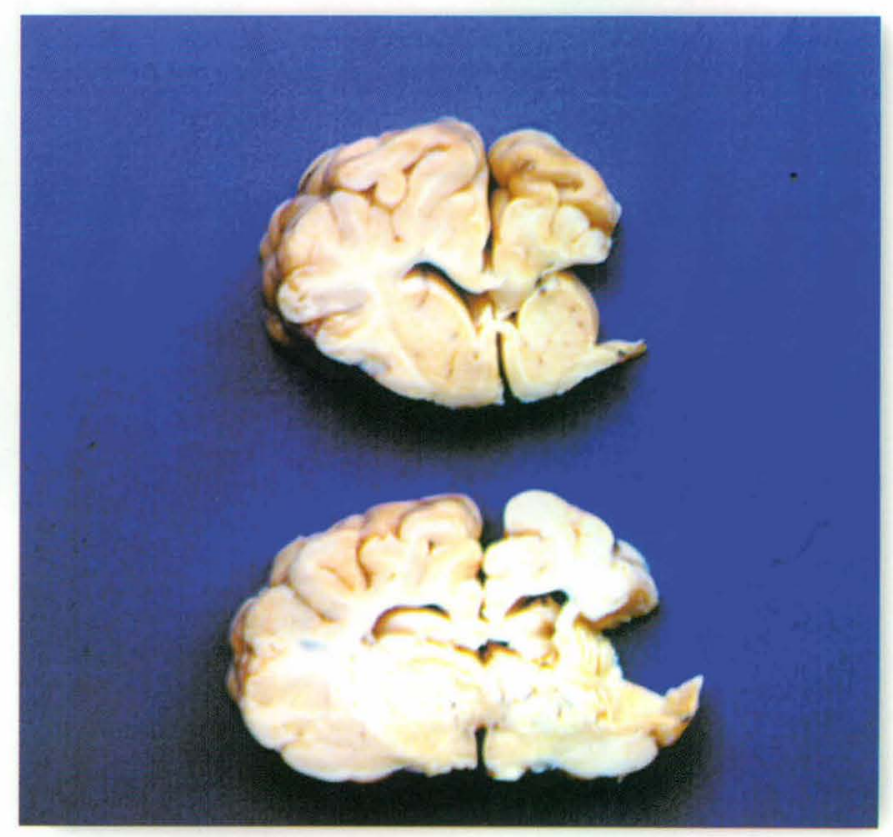

Figura 2 - Encéfalo de bezerro apresentando uma porencefalia na região temporal. 


\begin{tabular}{|l|}
\hline Quadro 6 - OBJETIVOS DO EXAME NEUROLÓGıCO \\
\hline Este animal apresenta anormalidades neurológicas? \\
Em caso afirmativo, qual é o local mais provável? \\
Quais são os diagnósticos diferenciais mais prová- \\
veis para lesões neste local? Associar as informações \\
relativas a identificação do animal (idade, espécie), evolu- \\
ção dos sinais clínicos e informações epidemiológicas. \\
Qual é o prognóstico? O tratamento é possível e viável \\
economicamente? Como prevenir a ocorrência desta \\
enfermidade em outros animais do rebanho?
\end{tabular}

\section{Quadro 7 - ETAPAS DO EXAME NEUROLÓGICO}

Identificação e anamnese

Exame físico

Identificação dos sinais

Interpretação das informações

Localização das lesões

Diagnósticos diferenciais

Exames complementares

Diagnóstico

Prognóstico

\begin{tabular}{|l|}
\multicolumn{1}{|c|}{ Quadro 8 - ANAMNESE } \\
\hline Início dos sinais clínicos \\
Evolução \\
Principais anormalidades observadas \\
Alimentação \\
Vacinação \\
Tratamentos realizados \\
Doenças anteriores \\
Número de animais acometidos \\
Ambiente e manejo dos animais \\
Número de mortes \\
\hline
\end{tabular}

\section{Quadro 9 - INÍCIO E PROGRESSÃO DOS SINAIS}

\section{AGUDO NÃO PROGRESSIVO:}

Enfermidades traumáticas e vasculares

\section{AGUDO PROGRESSIVO E SIMÉTRICO:}

Enfermidades metabólicas, nutricionais e tóxicas

AGUDO PROGRESSIVO E ASSIMÉTRICO:

Enfermidades inflamatórias (infecções), degenerativas e neoplásicas.
A evolução também é importante, pois diferentes enfermidades podem ser agrupadas em categorias que possuem, de modo geral, um padrão de evolução semelhante. Isto será muito eficaz para que se estabeleça o diagnóstico, pois muitas vezes, processos localizados no mesmo local do SNC irão produzir sinais clínicos semelhantes, mas poderão ser diferenciados pela sua evolução. Isto pode ser exemplificado da seguinte forma: um animal com um processo traumático afetando o cerebelo ou um outro com um abscesso localizado também no cerebelo, provavelmente apresentam sinais muito semelhantes (quando as áreas e a extensão da lesão forem parecidas), porém a evolução dos dois processos será muito diferente, o primeiro com início agudo e estacionário, e o segundo com evolução lenta.

Quanto maior for o conhecimento das enfermidades que acometem os animais, melhor será a anamnese realizada.

O exame físico de todos os sistemas deve sempre preceder um exame neurológico, pois permite diferenciar problemas concomitantes, assim como descartar alterações que possam sugerir anormalidades neurológicas. Sendo assim, os animais devem ser avaliados também quanto ao grau de desidratação, coloração de mucosas, palpação detalhada de todos os membros e coluna vertebral. Uma impotência funcional de um membro pode ser diferenciada entre uma fratura ou uma paralisia de nervo periférico, um decúbito lateral com grande apatia pode ser indicativo de uma lesão medular e de anemia ou desidratação severa. Tais aspectos podem parecer grosseiros na maioria das vezes, mas devem ser sempre lembrados. Salivação ou disfagia podem ser resultado de encefalites, botulismo ou devido a um corpo estranho na faringe ou esôfago. A cegueira pode ser resultado de encefalopatias de diferentes origens, ou de um destacamento de retina, ou, ainda, de uma severa catarata. O exame físico geral também permitirá observar possíveis alterações em outros sistemas que podem ser relacionadas às anormalidades neurológicas. Exemplo disso é a coloração ictérica das mucosas em alguns casos de encefalopatia hepática dos eqüinos.

Os objetivos de um exame neurológico são: confirmar a presença de um problema neurológico, localizar o problema, definir uma lista de diagnósticos prováveis, definir os exames complementares necessários, estabelecer o diagnóstico mais provável e o prognóstico, e possibilitar o plano terapêutico mais adequado. Paralelamente deve-se tomar as medidas preventivas necessárias para que o problema não ocorra em outros animais (Quadro 6). 


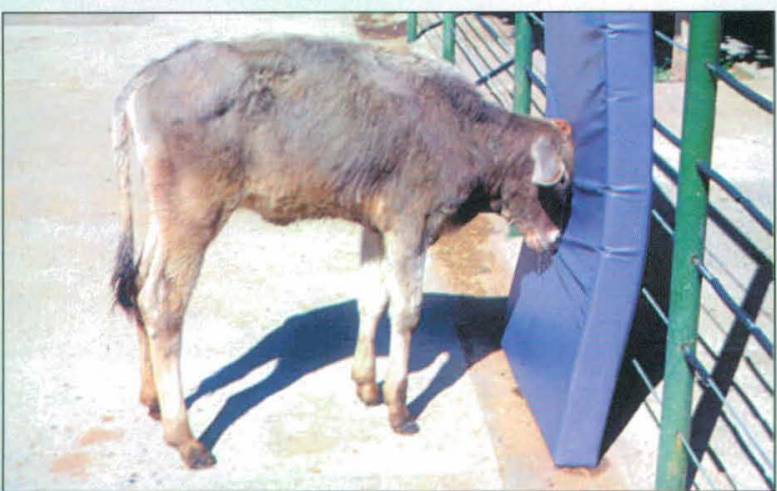

Figura 3 - Andar compulsivo e apoio da cabeça contra obstáculos em bezerro com polioencefalomalácia.

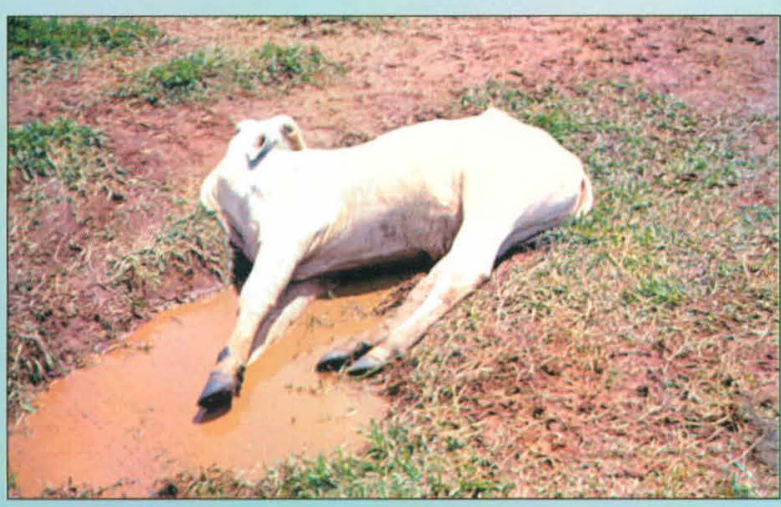

Figura 4 - Bovino com polioencefalomalácia: Decúbito, depressão mental e opistótono (cortesia Júlio A. N. Lisboa).

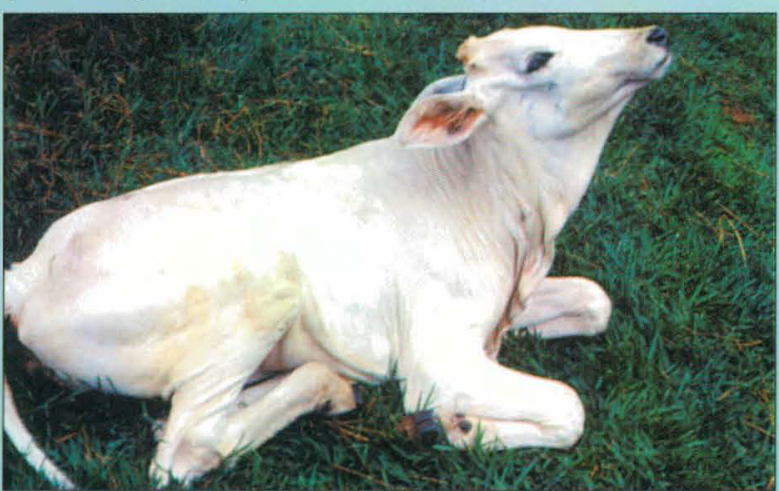

Figura 5 - Bezerro em decúbito e com discreto opistótono decorrente de encefalite viral (raiva).

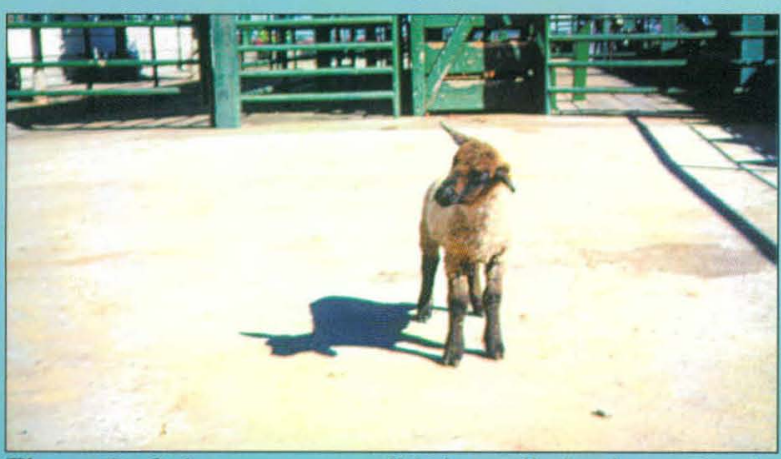

Figura 6 - Ovino com anormalidade vestibular decorrente de intoxicação com closantel (rotação de cabeça - "head tilt").

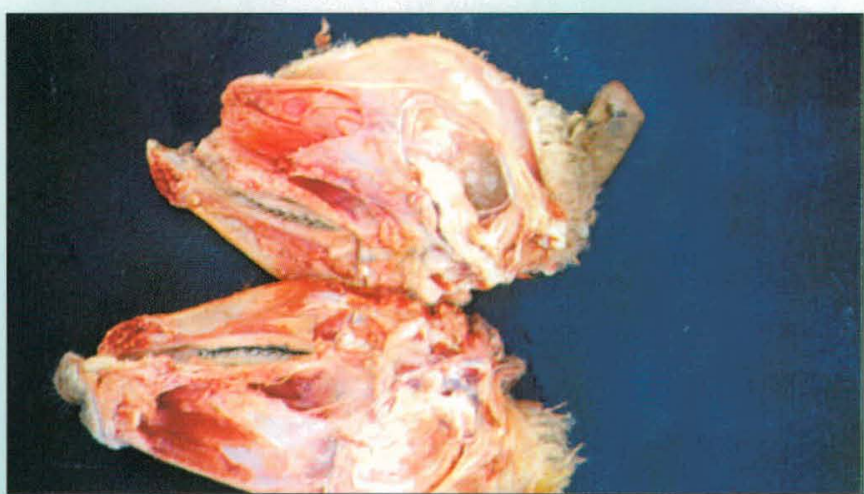

Figura 7 - Encéfalo de ovino com extensa lesão cerebral decorrente de cenurose (Taenia multiceps multiceps).

Deve-se lembrar que as informações devem ser inicialmente obtidas e posteriormente interpretadas. Uma tentativa precoce de interpretação, quando conduzida a um caminho errado, pode acarretar em uma precipitação na orientação do exame e em conseqüentes perdas de informações que poderiam ser importantes para um diagnóstico preciso (Quadros 7, 8 e 9).

É fundamental o uso de luvas durante o exame; este procedimento dará uma segurança muito grande ao examinador, pois a raiva é uma importante zoonose que apresenta diversas formas de manifestação clínica, nem sempre fáceis de serem inicialmente identificadas. Devemos lembrar que, algumas vezes, examinamos o animal apenas uma vez e não é possível retornar para acompanhar a evolução. O uso de luvas representa uma grande segurança, evitando aborrecimentos e preocupações futuras.

A utilização de uma ficha de exame (protocolo) permite realizar um exame completo, já que dificilmente esqueceremos alguma etapa até que estejamos totalmente familiarizados com os procedimentos de avaliação, além de facilitar o acompanhamento e os exames subseqüentes.

Para que existam alterações encefálicas, os seguintes aspectos precisam ser avaliados. Geralmente, quando alterações encefálicas estão presentes, ao menos dois desses itens que são a seguir descritos, devem apresentar alterações (Figuras 3, 4, 5, 6 e 7): comportamento (estado mental); posição da cabeça e integridade nas funções dos nervos cranianos.

A função encefálica é a primeira a ser avaliada, sendo o comportamento e o estado mental os primeiros aspectos a serem observados. Os dois estão estritamente relacionados e devem ser preferencialmente avaliados na presença de uma pessoa familiarizada com o animal, 


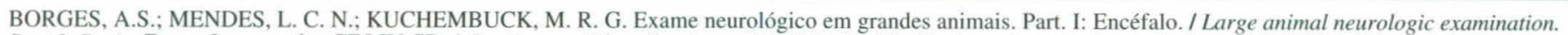
Part I: Brain. Rev. educ. contin. CRMV-SP / Continuous Education Journal CRMV-SP, São Paulo, volume 2, fascículo 3, p. 004 - 016, 1999.

\section{Quadro 10}

Para que existam alterações encefálicas os seguintes aspectos precisam ser avaliados: comportamento (estado mental), posicionamento da cabeça e integridade na função dos nervos cranianos. Geralmente, quando alterações encefálicas estão presentes, ao menos dois destes itens apresentam anormalidades.

\section{Quadro 11}

Os nervos cranianos podem ser rapidamente avaliados quando observamos a simetria facial, integridade da função visual, movimentação de orelhas, pálpebras e lábios, mastigação, movimentação da língua e deglutição. Dificilmente se estas funçōes estiverem íntegras existirão alteraçōes nos nervos cranianos. A presença de anormalidades em 2 ou mais pares de nervos cranianos é muito indicativo de anormalidades encefálicas enquanto alterações em apenas um par são sugestivas de lesões periféricas.

\section{Quadro 12}

Animais com lesão bilateral severa do nervo óptico estão cegos e em midríase.

que possa fornecer dados anteriores ao quadro clínico. Estas informações permitem diferenciar animais extremamente dóceis daqueles com apatia.

Utilizaremos o termo comportamento como a resposta observada a estímulos visuais, táteis e auditivos e enquadraremos o estado mental dentro deste item. $\mathrm{O}$ comportamento considerado normal é extremamente variável entre espécies, raças e indivíduos. Entre os com- ser responsáveis por acentuados níveis de depressão, chegando-se até o coma (Quadro 10).

Em seguida deve ser avaliada a posição da cabeça. A rotação da cabeça ("head tilt") é um sinal indicativo de lesão vestibular. A pressão da cabeça contra obstáculos ("head pressing") pode ser observada em diversas encefalopatias que afetem a função cerebral como, por exemplo, a polioencefalomalácia de ruminantes, a encefalopatia hepática dos eqüinos ou o trauma craniano. $\mathrm{O}$ andar em círculos pode ser observado geralmente em lesões unilaterais na região frontal.

Após essas etapas, deve ser realizada a avaliação dos nervos cranianos. Os 12 pares de nervos cranianos com seus respectivos nomes, funções e os testes a serem realizados são apresentados sob forma de tabela (Tabela 1). Observando esta tabela podemos notar que os 12 pares de nervos cranianos podem ser rapidamente avaliados. Devemos lembrar apenas que no conjunto são responsáveis pela olfação, visão, movimentação de orelhas, pálpebras, lábios, simetria e tônus da musculatura facial, preensão e mastigação de alimentos, movimentação de língua e deglutição. Se todas essas funções estiverem íntegras dificilmente iremos encontrar alteração nestes pares de nervos cranianos; já se alguma delas estiver alterada, poderemos realizar provas mais específicas para localizar a anormalidade em um ou mais pares de nervos cranianos (Quadro 11).

Algumas observações podem ser úteis na avaliação da função destes nervos. O nervo olfatório é difícil de ser avaliado em grandes animais. Ainda que raras e sem importância clínica, as afecções do nervo olfatório, quando ocorrem, são de difícil interpretação clínica devido as anormalidades no comportamento do animal.

portamentos considerados anormais incluem-se: emissão de sons anormais, andar compulsivo, andar em círculos, apoio da cabeça contra obstáculos, morder animais ou objetos inanimados e adoção de posturas bizarras. As anormalidades comportamentais geralmente estão associadas a alterações cerebrais. O estado mental deve ser avaliado cuidadosamente pois animais com enfermidades em outros sistemas poderão estar muito apáticos, sendo estes sinais muitas vezes confundidos com uma depressão no nível de consciência. Anormalidades cerebrais (tálamo, cápsula interna ou região frontal e mesencefálicas) podem

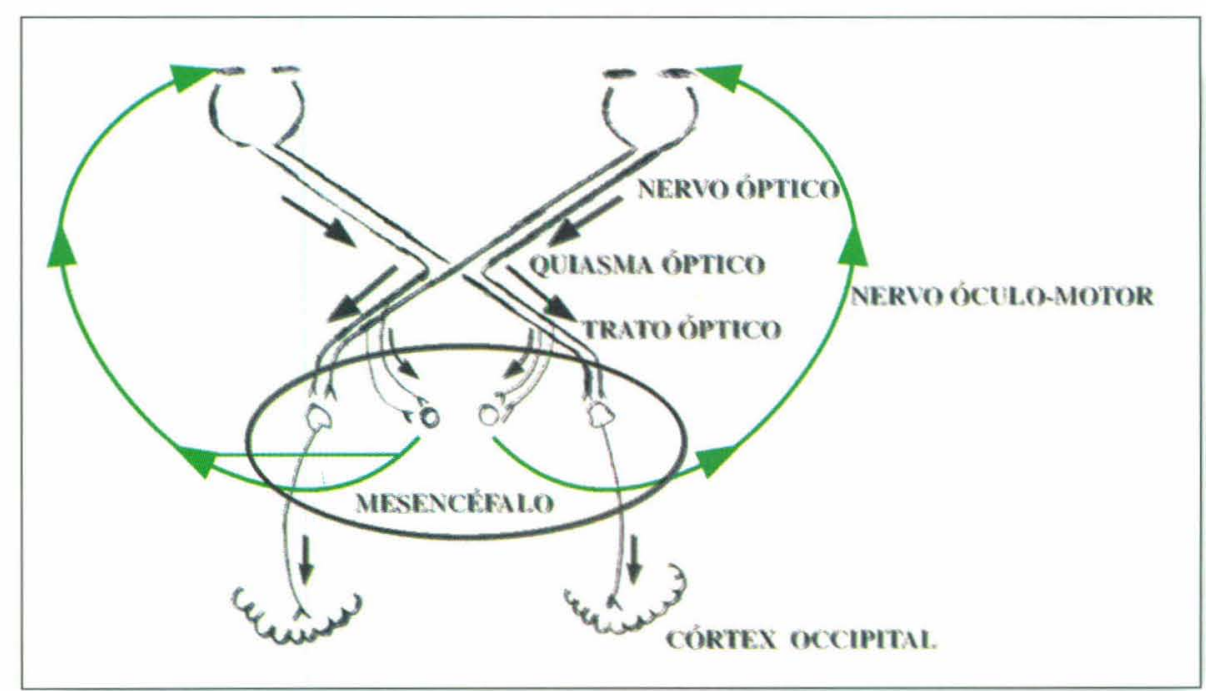

Figura 8 - Esquema das vias visuais e do reflexo pupilar (Modificado de MAYHEW, 1989). 


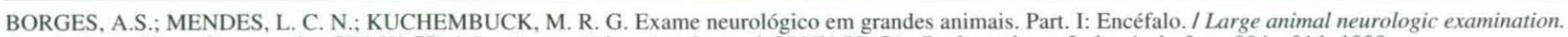
Part I: Brain. Rev. educ. contin. CRMV-SP / Continuous Education Journal CRMV-SP, São Paulo, volume 2, fascículo 3, p. 004 - 016 , 1999.

O segundo par de nervo craniano (óptico) pode ser avaliado por meio da percepção da integridade visual e também associado com o diâmetro pupilar (III par). Dificuldades parciais de visão decorrentes de anormalidades no sistema nervoso são difíceis de serem observadas e diagnosticadas, porém, os casos mais graves podem ser determinados com maior facilidade. Inicialmente, deve-se deixar o animal locomover-se livremente em um ambiente diferente daquele a que está acostumado, cuidando para que o animal não se machuque em algum obstáculo. Os animais cegos tendem a esbarrar ou ir de encontro a obstáculos.

A alteração visual também pode ser verificada pela prova de ameaça visual. Esta prova deve ser realizada com um gesto de ameaça em direção ao globo ocular do animal, que como resposta deve fechar a pálpebra (mecanismo protetor). Durante a realização desta prova, evitase a produção de deslocamento de ar em direção ao globo ocular ou mesmo o toque manual, o que acarretaria um reflexo palpebral, não relacionado ao processo visual e, sim, à captação sensitiva da região ocular e palpebral (nervo trigêmio) e à função efetora motora do nervo facial. É importante ressaltar que animais com severas alterações cerebelares podem apresentar diminuição ou ausência da resposta de ameaça visual, pois existem vias cerebelares importantes na sua modulação. A via aferente (impulsos que chegam ao SNC) da resposta de ameaça visual envolve as estruturas íntegras das vias visuais e sua interpretação no córtex occipital. A oclusão da pálpebra depende da via eferente (impulsos que deixam o SNC) composta pelo córtex visual contralateral e do sistema motor (ipsilateral ao estímulo) do nervo facial (Quadro 12 e Figura 8).

O reflexo pupilar também pode ser utilizado para avaliação do nervo óptico assim como também do nervo óculo-motor. Este reflexo é desencadeado em razão da integração das informações transmitidas pelo nervo óptico e nervo óculo-motor acarretando miose ou midríase. A retina capta a informação luminosa, transformando-a em impulsos elétricos que serão conduzidos pelo nervo óptico até o quiasma óptico onde um grande percentual de fibras sofre decussação (trocam de lado). A partir do quiasma óptico, essas informações trafegam pelo trato óptico passando pelo mesencéfalo, indo posteriormente ao córtex cerebral (formação de imagens). Durante a passagem pelo mesencéfalo, ocorre o estímulo do núcleo do nervo óculo-motor (III par de nervo craniano) ali localizado. O estímulo do núcleo do nervo óculo-motor irá gerar informações (transmitidas pelo nervo óculo-motor) que provocarão diminuição do diâmetro pupilar (miose). Quando o estímulo luminoso é pequeno, ocorrerá uma dilatação da pupila denominada de midríase.

A midríase ou miose são importantes para a maior ou menor captação de luz, melhorando a acuidade visual em ambientes com menor luminosidade ou protegendo as estruturas oculares em ambientes com grande quantidade de luz, respectivamente.

Este é um exemplo de um arco reflexo mediado por um nervo sensitivo (óptico) e um nervo motor (óculomotor) que permite a avaliação da integridade das estruturas envolvidas. Portanto, para que ocorra a miose após um estímulo luminoso, deve haver integridade destas vias até a efetuação do reflexo. Um reflexo pupilar adequado não implica necessariamente que o animal esteja enxergando, pois, para que isto ocorra, as vias devem estar íntegras até o córtex occipital.

Ao colocarmos um animal em uma sala escura e iluminarmos o olho direito com uma lanterna, deverá ocorrer a diminuição do diâmetro da pupila testada (miose ipsilateral) e também irá ocorrer uma miose discreta na pupila esquerda (reflexo consensual). O contrário ocorrerá quando iluminamos o outro olho. Este mecanismo de fechamento consensual da pupila devese ao cruzamento das fibras, ocorrido no quiasma óptico e também das conexões entre o mesencéfalo esquerdo e direito. Em virtude da posição dos globos oculares (em grandes animais) é complicado para o examinador realizar sozinho a avaliação do reflexo pupilar consensual e direto ao mesmo tempo. Podemos perceber, pela breve descrição das vias visuais, que lesões encefálicas localizadas na região de córtex occipital podem acarretar cegueira sem anormalidades do reflexo pupilar, já que as vias que envolvem esse reflexo estão localizadas mais rostralmente, sendo um exemplo disto a polioencefalomalácia dos bovinos.

Como na maioria das vezes observamos estes animais em ambiente aberto e não em uma sala escura, precisamos fazer uma modificação no procedimento do exame. Deve-se fechar os dois olhos com a mão e observar o reflexo pupilar de cada um de forma individual (mantendo sempre um deles fechado), com o posicionamento da cabeça do animal em direção ao sol. Não devemos fechar apenas um olho e em seguida abri-lo, pois o reflexo consensual originado no olho deixado aberto irá diminuir o reflexo a ser testado.

O diâmetro pupilar também é influenciado pelos músculos dilatadores da pupila, inervados por fibras simpáticas originadas do gânglio cervical cranial (devido a este fato ocorre a dilatação pupilar quando os animais estão com medo ou excitados). 
BORGES, A.S.; MENDES, L. C. N.; KUCHEMBUCK, M. R. G. Exame neurológico em grandes animais. Part. I: Encéfalo. / Large animal neurologic examination. Part I: Brain. Rev. educ. contin. CRMV-SP / Continuous Education Journal CRMV-SP, São Paulo, volume 2, fascículo 3, p. 004 - 016 , 1999.

Tabela 1 - Função, testes de avaliação e sinais de anormalidades dos nervos cranianos.

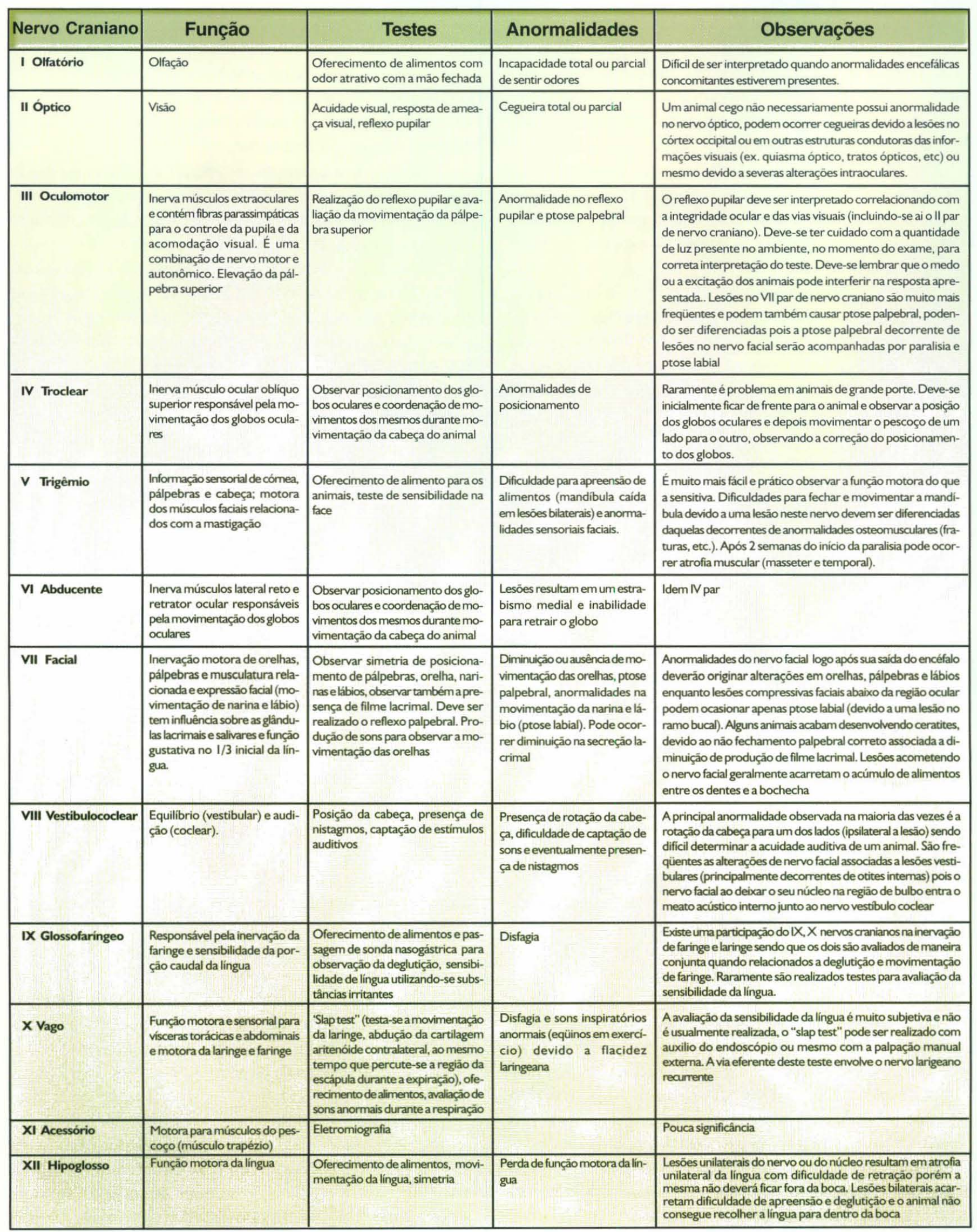




\section{Quadro 13}

O sistema vestibular tem a função de integração animal e ambiente no que diz respeito a gravidade. Ajuda a manter a posição dos olhos, tronco, membros e cabeça durante os movimentos. Contém receptores no ouvido interno, nervo vestibular, núcleo vestibular, cerebelo e tratos vestibulares na medula espinhal.

Lesões simpáticas (os locais mais freqüentes são bolsa gutural ou lesões cervicais) podem acarretar a denominada síndrome de Horner que consiste em discreta ptose da pálpebra superior, miose e discreta protrusão da terceira pálpebra. Associado a esses sinais, observa-se sudorese na base da orelha e pescoço.

O sétimo par de nervo craniano é o que apresenta alterações com maior freqüência. Possui seu corpo celular localizado no tronco encefálico, sendo responsável pela função motora da orelha, pálpebra e lábios. É importante diferenciarmos as lesões localizadas no corpo celular (núcleo do nervo facial localizado no tronco encefálico) daquelas ocorridas no seu trajeto, pois possui grande importância na localização da enfermidade e conseqüente diagnóstico. Lesões localizadas na região de tronco encefálico geralmente são acompanhadas por envolvimento de outros pares de nervos cranianos em conseqüência da proximidade na localização de seus núcleos. Lesões periféricas podem

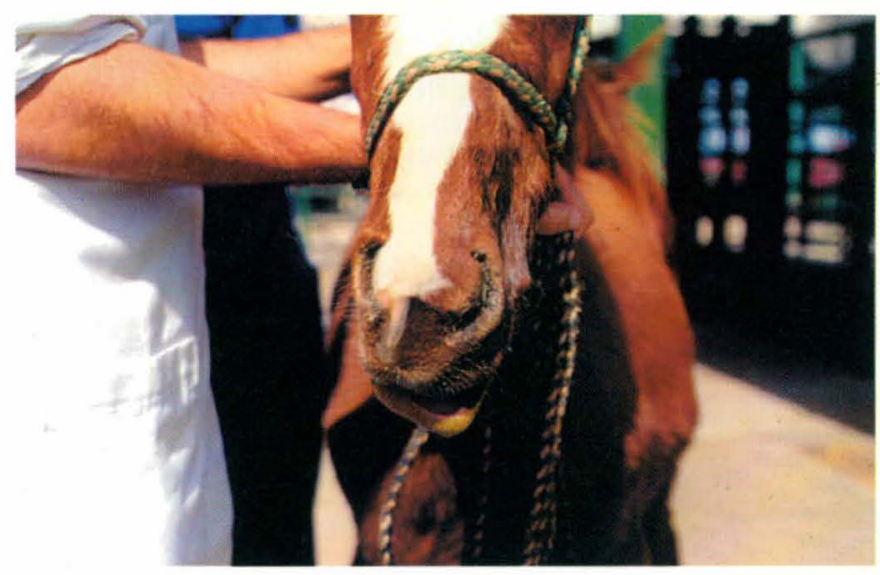

Figura 9 - Paralisia periférica unilateral do ramo bucal do nervo facial: observa-se a ptose labial.

ocorrer em virtude de alterações durante o trajeto desse nervo, que é bastante superficial. O reflexo palpebral serve para avaliar a função motora do nervo facial (Tabela 1 e Figuras 9, 10 e 11).

Nistagmos devem ser avaliados quanto a sua direção de movimento rápido. Sempre em lesões vestibulares periféricas, e geralmente com enfermidades vestibulares centrais, a fase rápida do movimento é contrária ao lado da lesão. Nistagmos originados de doenças vestibulares periféricas são sempre horizontais ou discretamente rotatórios, enquanto na doença central estes podem ser em qualquer direção. Apesar de ser possível, durante as fases agudas de doenças vestibulares, que nistagmos espontâneos estejam presentes com a cabeça em posi-

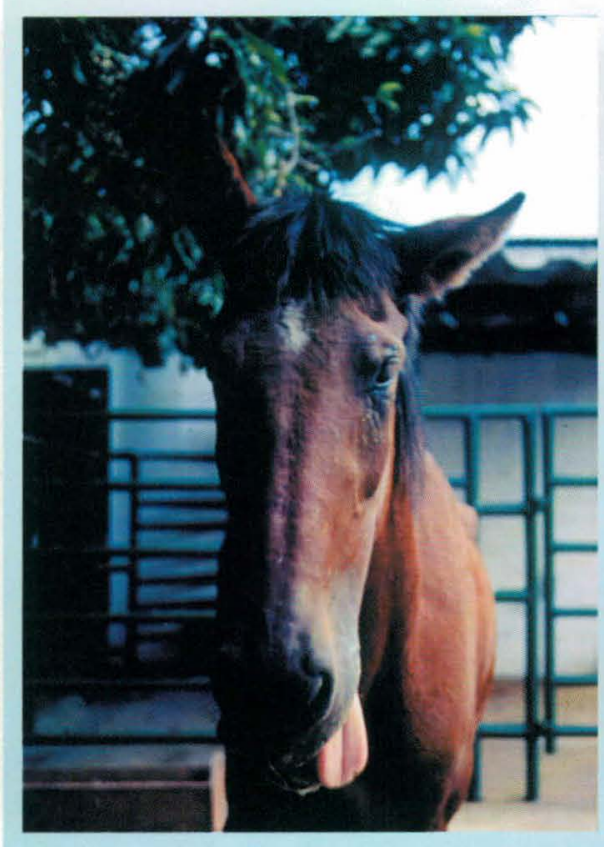

Figura 10

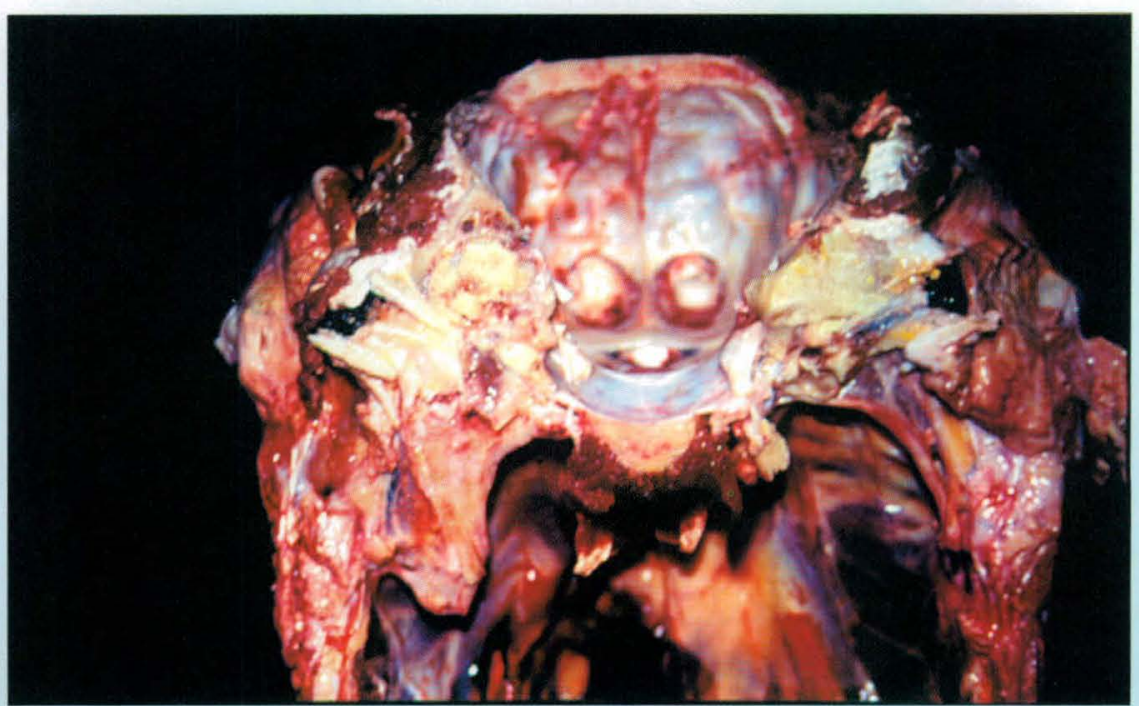

Figura 11

Equiino com ptose do pavilhão auditivo, ptose palpebral, ptose labial e paralisia da língua decorrentes de severa otite e acometimento de mais de um par de nervo craniano (cortesia Ivan R. Barros). 


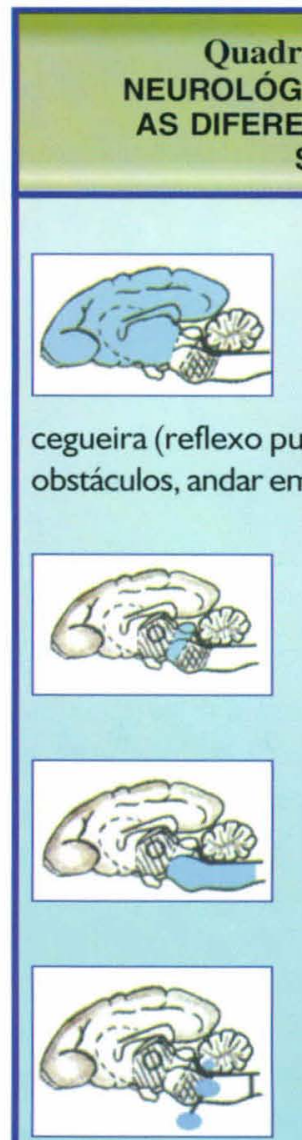

SÍNDROME CEREBRAL: anormalidades locomotoras (podem ser discretas), estado mental (depressão) e comportamento alterados, respiração irregular, cegueira (reflexo pupilar normal), pressão da cabeça contra obstáculos, andar em círculos (geralmente lesões unilaterais).

SÍNDROME MESENCEFÁLICA: Anormalidades locomotoras, depressão mental, midríase não responsiva ou miose (visão normal), estrabismo.

SÍNDROME PONTOBULBAR: Anormalidades locomotoras, alteração em diversos nervos cranianos, depressão mental.

\section{SÍNDROME VESTIBULAR: Centra} (nistagmos horizontais, rotacionais, verticais ou posicionais, déficits nos nervos cranianos: V, VI e VII; podem ocorrer sinais cerebelares). Periférica (nistagmos horizontais ou rotacionais, possível déficit no VII par de nervo craniano. Tanto a síndrome central quanto a periférica podem apresentar perda de equilíbrio, quedas, rotação de cabeça e estrabismo.

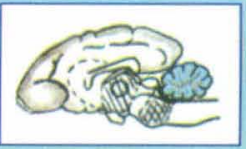

CEREBELAR: tremores de intenção na cabeça, anormalidades locomotoras (hipermetria), nistagmos, alteração na resposta de ameaça visual, aumento da área de sustentação do corpo (ampla base).

MULTIFOCAL: Presença de sinais clínicos que refletem mais de uma síndrome.

Obs: É importante ressaltar que nem todos os sinais estarão presentes em determinadas situações e que as anormalidades caracterizadas por sinais multifocais são as mais freqüentemente encontradas em animais de grande porte.

\section{Quadro 15}

Opistótono é um termo utilizado para designar a posição de extensão caudal da cabeça e pescoço devido a um espasmo muscular e geralmente é decorrente de lesões cerebelares ou cerebrais. ção de descanso, pode ser necessário nestas ocasiões, manter a cabeça em postura anormal para a indução dos mesmos (Quadro 13).

As alterações encefálicas podem acarretar distúrbios locomotores, variando de uma discreta incoordenação motora até andar compulsivo ou mesmo o decúbito permanente. Essas alterações estão presentes por causa de lesões nos núcleos motores, sendo assim um eqüino com abscesso ou com leucoencefalomalácia pode apresentar alterações locomotoras variando

\section{Quadro 16}

A pressão da cabeça contra obstáculos "head pressing" pode ser observada em diversas encefalopatias que afetem a função cerebral como por exemplo a polioencefalomalácia de ruminantes, a encefalopatia hepática dos eqüinos ou o trauma craniano.

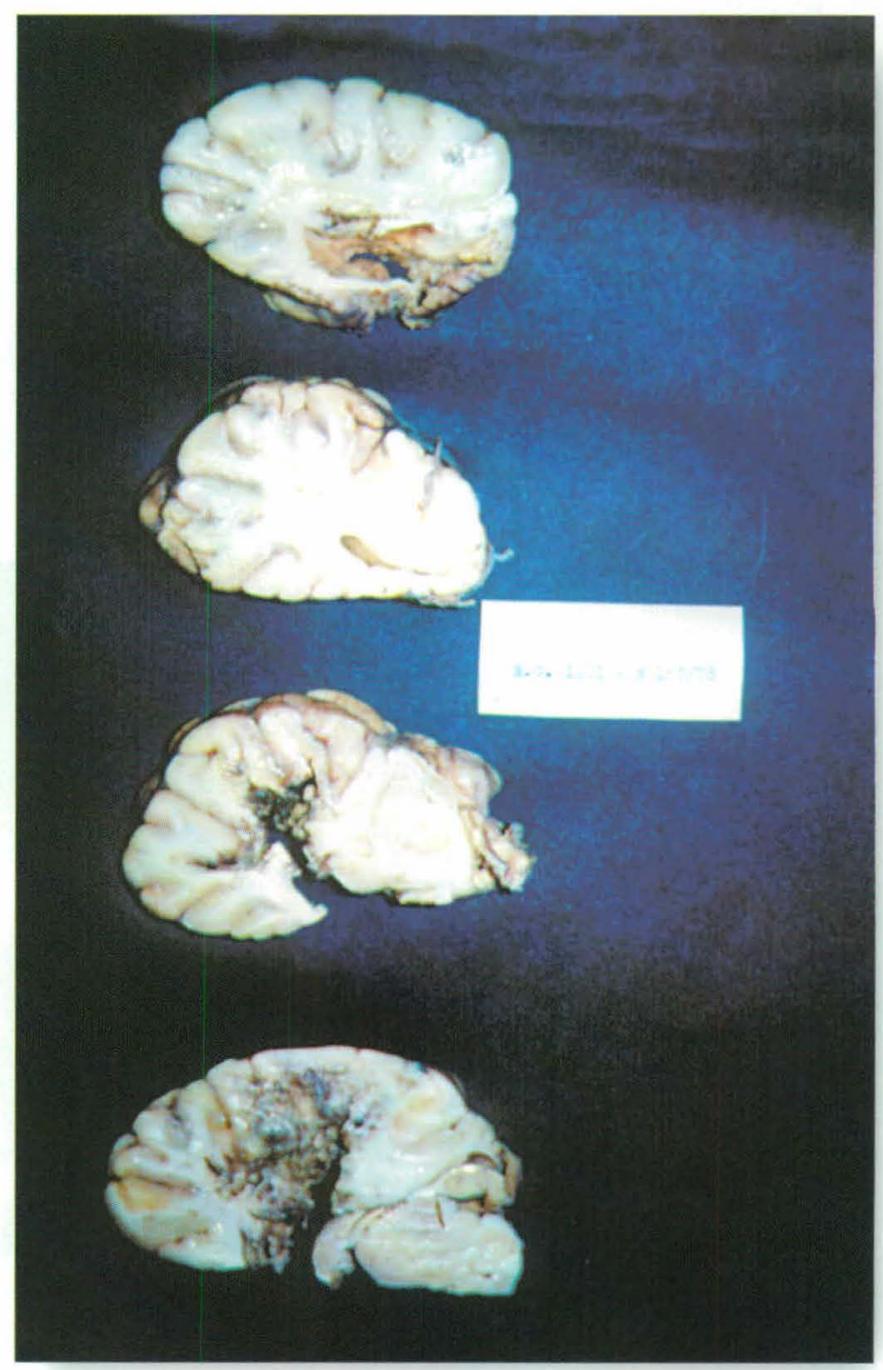

Figura 12 - Lesões encefálicas difusas decorrentes de leucoencefalomalácea eqüina (cortesia Maria Cecília Rui Luvizotto). 


\section{Quadro 17}

\begin{tabular}{l|l}
\hline ANORMALIDADES NESTAS FUNÇÕES... & SUGEREMANORMAUDADESNESTASESTRUTURAS \\
\hline Visão & II, córtex cerebral occipital (ou as vias entre os dois), olhos \\
& \\
Resposta de ameaça visual & II, VII, cérebro e cerebelo \\
Tamanho e simetria pupilar & II, III, sistema nervoso simpático \\
Reflexo pupilar & II, III \\
Posição e movimento do globo ocular & III, IV, VI, VIII \\
Normalidade e simetria da musculatura facial & $\mathrm{V}$ \\
Reflexo palpebral & $\mathrm{V}, \mathrm{VII}$ \\
Movimentação da orelha, pálpebra e lábio & $\mathrm{VII}$ \\
Sensibilidade facial & $\mathrm{V}$ \\
Tonus mandibular normal & $\mathrm{V}$ \\
Pálpebras são mantidas abertas em posição normal & $\mathrm{III}, \mathrm{VII}$, sistema nervoso simpático \\
Resposta normal aos sons & $\mathrm{VIII}$ \\
Animal deglute corretamente e move adequadamente a língua & $\mathrm{IX}, \mathrm{X}, \mathrm{XII}$ \\
Tônus lingual está normal e a musculatura da língua está simétrica & $\mathrm{XII}$
\end{tabular}

de uma discreta incoordenação até um decúbito. Quando estão presentes alterações locomotoras (de origem neurológica) sem outras anormalidades encefálicas, o sítio de alteração deve estar localizado na medula espinhal ou nervo periférico (Quadros 14, 15, 16 e 17).

As anormalidades observadas dependem principalmente do local afetado. Portanto, a identificação do local é muito importante para a caracterização do processo.
São raros os casos em que ocorre lesão de uma determinada estrutura encefálica, já que grandes animais, com maior freqüência, apresentam lesões difusas no encéfalo. Os processos infecciosos, metabólicos, tóxicos ou degenerativos promovem lesões difusas acometendo grandes extensões do encéfalo, sendo os processos de ocorrência mais freqüentes (Figura 12).

\section{SUMMARY}

In this first part of this review on neurological examination of large animals, it is presented information regarding the neuroanatomy, neurophysiology and function of the brain. The next part of this review will deal with the examination of the spinal cord of these animals.

Key words: neurology, brain, spinal cord, reflex arc, cranial nerves, nervous system.

\section{AGRADECIMENTOS}

Cristiano de Carvalho (desenhos), Alexandre Pereira (computação gráfica), Luciana Felício de Paula, Juliana Regina Peiró e Alessandra Gonçalves (revisão de texto). 


\section{BIBLIOGRAFIA DE APOIO}

1 - BAKER, J. C. Bovine neurologic diseases. The Veterinary Clinics of North America, v. 3, n. 1, 1987, 216 p.

2 - BEAR, M. F.; CONNORS, B. W.; PARADISO, M. A. Neuroscience exploring the brain. Baltimore: Williams \& Wilkins, 1996, 666 p.

3 - BORGES, A. S.; SAPATERA, A. C.; MENDES, L. C. N. Avaliação dos reflexos espinhais em bezerros, Ciência Rural, v. 27, n. 4 , p. $613-7,1997$.

4 - BORGES, A. S.; VASCONCELOS, R. O.; MENDES, L. C. N.; ALVES, A. L. G. Espinha bífida com meningomielocele e mielodisplasia em ruminantes. Arquivo Brasileiro de Medicina Veterinária e Zootecnia, v. 49, n. 6, p. 685-92, 1997.

5 - BORGES, A.S.; LUVIZOTTO, M.C.R.; ALVES, A.L.G.; GARCIA, S.D. Leucoencefalomalacia - Relato de 10 casos. In: ENCONTRO NACIONAL DE PATOLOGIA VETERINÁRIA, Belo Horizonte 1995. Anais. 1995. p. 98.

6 - BRAUND, K. G. Clinical syndromes in veterinary neurology. 2 ed. Saint Louis: Mosby, 1994, 477 p.

7 - BREWER, B. D. Examination of the bovine nervous system. The Veterinary Clinics of North America. Bovine neurologic diseases, v. 3 , n. 1, p. 18-27, 1987.

8 - BRYANT, J. O. Rabies. The Horse. July, p. 51-3, 1999

9 - CHRISMAN, C. L. Problems in small animal neurology. 2 ed. Philadelphia: Lea \& Febiger, 1991, 526 p.

10 - DE LAHUNTA, A. Veterinary neuroanatomy and clinical neurology. 2 ed. Philadelphia: Lea \& Febiger, 1983, 471 p.

11 - GEISER, D. R.; HENTON, J. R.; HELD, J. P. Tynpanic bulla, petrous temporal bone, and hyoid apparatus disease in hor- ses. Compendium of Continuing Education, v. 10, n. 6 , p. $740-55,1988$.

12 - GELATT, K. N. Veterinary ophthalmology. 2 ed. Philadelphia: Lea \& Febiger, 1991.765 p.

13 - KNOTTENBELT, D. C. Equine neurological disease and dysfunction: a diagnostic challenge for the practitioner. Part 1: Objectives and limitations of a neurological examination. Equine Veterinary Education, v. 8, n. 4, p. 196-9, 1996.

14 - KNOTTENBELT, D. C. Equine neurological disease and dysfunction: a diagnostic challenge for the practitioner. Part 2 : The clinical neurological examination. Equine Veterinary Education, v. 8, n. 5 p. 260-70, 1996.

15 - MARTIN, C. L.; KASWAN, R.; CHAPMAN, W. Four cases of traumatic optic nerve blindness in the horse. Equine Veterinary Journal, v. 18, p. 133-7, 1986.

16 - MAYHEW, I. G. Large animal neurology: a handbook for veterinary clinicians. Philadelphia: Lea \& Febiger, 1989, $390 \mathrm{p}$.

17 - MAYHEW, I. G. Neuro ophtalmology, In: BARNETT, K. C.; CRISPIN, S. M.; LAVACH, J. D.; MATTHEWS, A. G. Color atlas and text of equine ophtalmology. London: Mosby-Wolfe, 1995, p. 215-22.

18 - SHELL, L.G. The cranial nerves of the brain stem. Progress in veterinary neurology. v. 1, n. 3, p. $233-45,1990$

19 - SIMPSON, S. Watchwords of the neurologic examination. Progress in veterinary neurology. v. 1, n. 1, p. 8-27, 1990.

20 - SMITH, J. M.; COX, J. H.; DEBOWES, R. M. Central nervous system disease in adult horses. Part I. A data base. Compendium of Continuing Education, v. 9, n. 5, p. 561-7 1987.

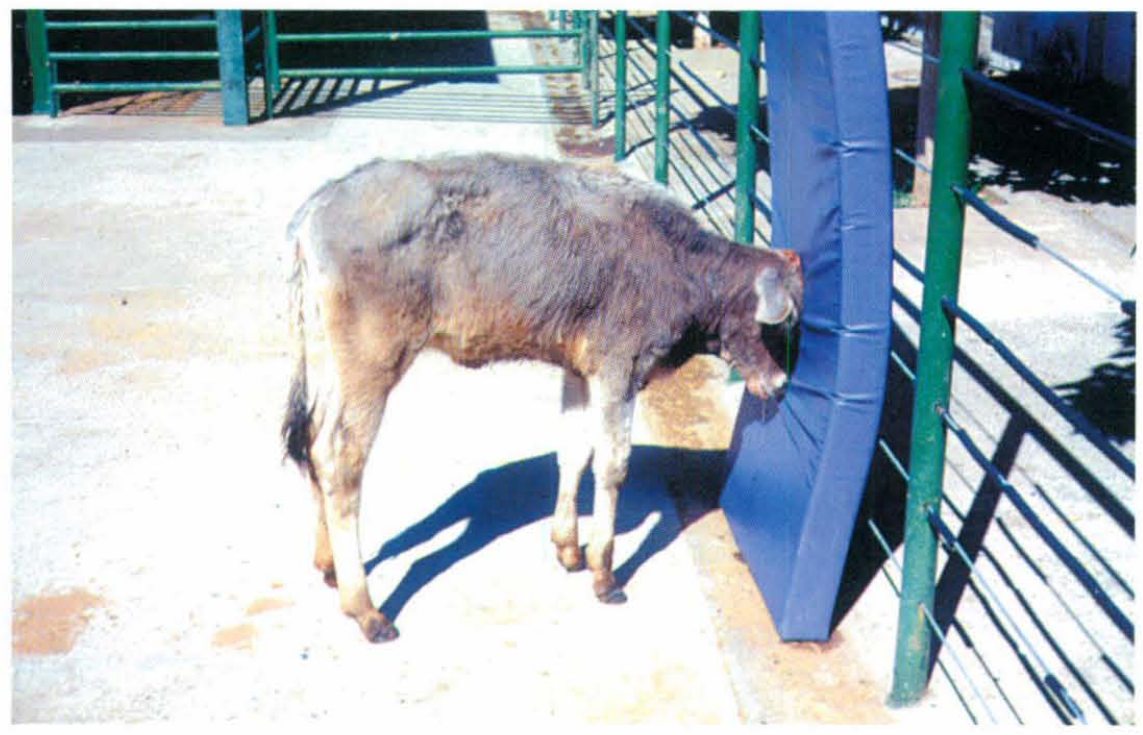

